\title{
A Review of the Airport-Low Cost Airline Relationship
}

\author{
IAN HUMPHREYS \\ Loughborough University \\ STEPHEN ISON \\ Loughborough University \\ GRAHAM FRANCIS * \\ Waikato University
}

\begin{abstract}
This paper seeks to review the airport-airline relationship in the light of the growth in the low cost sector, identifying important issues that airport management should consider when negotiating with low cost airlines. Airports have responded to the potential opportunities that have arisen from the growth of low cost airlines. The low cost model has implications for the airline-airport relationship, forcing airports to negotiate contracts which significantly reduce aeronautical revenues whilst seeking to address this short fall by commercial revenues via increased passenger numbers. Airports have sometimes found it difficult to turn increased passenger volume into additional revenue.
\end{abstract}

\section{Introduction}

The aim of this paper is to assess the impact of the growth of low cost carriers on airports. The low cost model has changed the nature of the airport-airline relationship and this paper identifies important issues that airport management should consider when negotiating with low-cost airlines.

The low cost carrier (LCC) sector has seen considerable growth (O'Connell and Williams, 2005) although the market sector is also characterised by the volatility of many of the new low cost entrants. There is considerable economic pressure on airports often associated with privatization and commercialization which has led airports to examine the various ways of making viable returns to their stakeholders. Airports have increasingly recognized that non-aeronautical revenues are an important source of revenue but are dependent on the airline choice of airport to attract passengers. The expansion of the low cost sector is seen as a way of increasing passenger numbers most notably by smaller,

* Contact author: Graham Francis, Senior Fellow, Department of Accounting, Waikato Management School, Waikato University, Hamilton, New Zealand. E-mail: gajf@waikato.ac.nz Tel + 64 (0) 7 8562889, Fax + 64 (0) 78384332 . 
regional airports. Additionally, local and regional governments have seen the attraction of LCC as being beneficial in developing the local/regional economy (Francis et al., 2004).

The growth of low cost airline services has had a profound effect on secondary airports and in recent years, there is evidence that a network of scheduled services that utilise secondary airports has emerged in parallel with the traditional network of major airports. This new network has begun to grow in major markets worldwide. Secondary airports are seen as ideal by LCCs since they typically offer the right conditions in which this specific type of carrier can prosper namely, low airport and handling charges, less congestion both in terms of the runway and surface access capacity for growth, available slots (Barrett, 2004), and the capability to enable swift aircraft turnaround times, a factor that enables low cost operators to gain better utilisation from their aircraft. Forecasts of further low cost airline growth and the stagnation of traditional legacy airlines has led some to suggest that low cost airlines might completely change the way in which airports are utilised (de Neufville, 2004).

The paper is predominantly EU specific, based on the fact that the EU has experienced a rapid growth in the low cost sector in recent years and is likely to continue so given the expansion of the EU following the accession of 10 additional countries in 2004 and the open skies policy post 1995. In the first year of EU accession, the number of low cost flights rose 24\% (Airliner World, 2005). The growth has implications for the airport sector and has resulted in the rise of a viable network of secondary airports.

\section{Methodology}

Primary research for this paper has been obtained through a number of semi-formal interviews with airport and airline managers in the UK, Italy, Germany, France, Slovakia, Poland, Czech Republic and Denmark. The managers have been assured that their comments would remain anonymous. Secondary sources of information for this paper have been gathered from a review of current academic literature and information gleaned from published industry sources.

Given the dynamic nature of the aviation sector and in particular the evolving nature of LCCs and airport networks this paper can only provide a snap shot at a particular point in time.

\section{The business relationships between airports and LCCs}

In recent years, there has been a move towards the privatization and/or commercialization of airports and this has led airport managers to seek different ways of making economically viable returns for their shareholders. Traditionally, airports were dependent on a combination of governmental funding and revenue from airlines by charging them socalled aeronautical charges for the use of their services. Although there is a variety of practice worldwide, typically, airports will charge airlines a weight related fee to land their aircraft, a fee per passenger that passes through the terminal, aircraft parking charges and charges for office space. Additional charges relate to ground handling and this may be provided by the airline itself or by a third party ground handling company (or companies). Airports issue published charges, yet research has revealed that these offer a guideline and 
in many cases, the amount actually paid by the airline can be somewhat less, depending on the volume of flights and whether or not the route is a new service (Francis et al., 2003 and Caves and Gosling, 1999).

Whilst airports still receive aeronautical revenues, the changing airport-airline relationship has seen non-aeronautical revenue from commercial sources becoming increasingly significant (Gillen and Lall, 2004 and Barrett, 2004). Such revenues are still dependent on the airline choice to bring passengers to a particular airport. Airports have seen LCC as a way of increasing the number of passengers passing through their terminals and increasing revenues through passenger spending, most notably in terms of retail and car parking charges.

\section{$4 \quad$ Issues airport managers need to consider}

It is difficult to generalise on the impact that LCCs have had and will have on airports, not least since airports have been impacted in different ways and will have different issues to face, depending upon their unique market context. For this reason, the authors examine the issues raised by the growth in the low cost airline market drawing on a synthesis of specific airport examples. In addition, the authors identify a number of important issues that airports need to consider when entering into negotiations with LCCs. There are a number of issues which need to be faced by airport management when considering accommodating the operation of LCCs and it is to these issues that the paper now turns.

\subsection{Continual market monitoring}

Airport management needs to keep the low cost airline market under continual review and reassess whether they wish to accommodate LCCs or not. Some airports have stated firmly that they will not welcome LCCs and that they prefer to focus on business passengers and charter services. The growth of the low cost phenomenon has led some airports to reevaluate this position and to begin to accommodate and provide for low cost services. Recently, Indian LCC, Air Deccan, has been granted access to Dubai airport, where previously, the airport had stated that low cost was not part of its target market. It is possible that low cost services to neighbouring airports indicated to airport management that if they did not welcome LCCs, then a segment of the market may migrate to nearby Sharjah.

\subsection{The volatile nature of the low cost sector}

The low cost sector is somewhat volatile both in terms of revenue streams and the networks available. In terms of market contestability, the LCC sector is characterised by a high number of route entries, and operators going out of business or transferring (or threatening to transfer) their operations to other airports (Lawton and Solomko, 2005). The European airline market has demonstrated a volatility and fragility in terms of service provision with an analysis of OAG data revealing that $28 \%$ of the low cost airline services which started between 1997-2002 being withdrawn, compared to an average of 2\% for full fare scheduled operations. Air Polonia, Volare, Dutch V Bird are just three of the operators who have ceased operation in 2005.

Ryanair operated services to Manchester Airport but withdrew a number once the initial financial package had expired. The airline developed new services from 
neighbouring Liverpool John Lennon and Leeds-Bradford airports, yet the airport stated that any deals it made should be available to all airlines and that it could not show preferences to some users over others. easyJet and Ryanair have continued to develop services at Liverpool John Lennon airport and in 2004/5, Manchester attracted bmibaby and Jet 2 to operate networks of services, plus low cost services from SkyEurope, Monarch Scheduled, Hapag-Lloyd express and Air Berlin. Manchester has recognised the significance of the sector in terms of volume and growth and has begun to work with these operators with the proviso of seeking win-win agreements that will help establish traffic.

LCCs tend to be footloose in nature and have less commitment to their route networks than legacy airlines and can change the choice of airports at short notice. This allows the airlines a tough negotiating position to help maintain their cost advantage. The impact on the airport is that the benefits from attracting LCCs are uncertain and may be short lived.

A small publicly owned Southern European airport used considerable financial incentives to attract a LCC on the premise that this would boost inbound tourism and the local economy. The airport made a loss during initial months of operation and many passengers arrived at the airport but travelled onwards outside the region to alternative tourist destinations. As such, neither the airport or the local community benefited financially. The airport management subsequently wished to renegotiate the agreement for reduced aeronautical fees not least because public subsidy was withdrawn. The LCC refused to renegotiate terms that were agreed for 10 years and ultimately withdrew their service. This raises questions for airport management with respect to careful evaluation of long term agreements with airlines and the associated benefits.

There is a new development which can be noted, namely where a LCC is offering a particular service on a route where there is already an operator. The question raised is whether this is viable in the medium to long term? Clearly, this raises issues for the airport since they would be ill-advised to invest in new capacity on the basis of parallel routes. For example, bmibaby and easyJet have begun to compete head to head from Nottingham East Midlands Airport, Jet 2 have begun services from Manchester, some of which are served by other LCCs at that airport and Ryanair have begun to serve destinations from easyJet bases at Liverpool and Luton, although these are to the same place but not to the exact same destination airport.

\subsection{Significance of non-aeronautical revenue}

Any airport that seeks to attract LCCs through reduced airport charges and marketing assistance needs to have sufficient retail and car parking capacity to be able to create commercial revenue streams in order to make the accommodation of low cost traffic a viable proposition. If sufficient retail spend is not achieved from passengers, then it is possible that an airport can attract new services but ultimately lose money. The timescale for break-even needs to be carefully calculated by airport management and revenue streams need to be monitored. A number of UK airports monitor passenger spend airside via boarding pass information, enabling them to identify passenger spend by route, time of day, and type of shop. This information helps to drive decisions about the effectiveness of the retail offer and it provides important real data with which to enter into negotiations with LCCs. One airport reported that the amount a particular airline was charged could be related to forecast and actual retail spend. Airport management suggested this was particularly important for when airport contracts were up for renegotiation by the airline. It 
is important for airports to note that both the amount spent and nature of purchases made by low cost passengers may be different from that experienced from existing passengers.

Ideally, an airport requires existing retail and car parking capacity in order to maximise spend by passengers, however, if new facilities need to be built, then the associated costs must be taken into account when calculating any deal with an airline. A small airport located in Europe attracted several LCCs by offering reduced landing charges. Its financial situation deteriorated in the first instance due to a lack of appropriate retail facilities. The low total volumes of traffic made it difficult to make a satisfactory return and to justify the costs of providing retail facilities. With a rise in traffic volumes, it has become more attractive to retailers. Such issues need careful consideration by management. Established airports can attract LCCs and improve retail performance by improving spend through existing facilities, whereas airports with limited existing traffic may need to create the facilities in the first place and may be limited to the nature and potential retailing opportunities by the overall passenger throughput.

Whilst the low cost model is incompatible with the airlines being willing to pay directly for the provision of facilities in their aeronautical charges, it does not mean that a point can not be reached where the airport and airline achieve a mutually beneficial agreement. LCCs must not be viewed as a panacea for every airport but there are many relatively small underutilised airports that could benefit from an appropriate relationship.

\subsection{Capacity to cope with the LCCs}

Clearly, an issue faced by airports is their ability to cope with an influx of LCCs, not least in terms of airport capacity, both terminal and runway. The question is what benefits are derived from LCCs in relation to the short and long term costs of accommodating them. If an airport is underused, it may welcome LCCs because it can do so at low marginal cost per passenger. The difficulty arises when LCCs wish to expand their operations beyond the existing airport capacity. The need for new terminal facilities needs to be provided or the airport faces the risk of losing the LCC. For example, at Nottingham East Midlands Airport when easyJet, Ryanair and bmibaby's low cost growth occurred, airport management expanded terminal facilities by providing a low cost "fabric" structure. Management argued that this was the only way to meet the cost of expansion based on the low aeronautical revenues paid by the LCCs.

In terms of major airports, Stansted has built, and Amsterdam is building, new facilities specifically for LCCs, devoid of air bridges. In addition, the new terminal building at Amsterdam will not have facilities for transfer passengers, and will be planned to accommodate swift aircraft turnarounds freeing up premium terminal space for its more traditional airline clients (Nicholls, 2005).

\subsection{Tensions between incoming and incumbent airlines}

Tension can often exist between the incumbent airline operators and the incoming LCCs. This is something which airports need to be aware of and be proactive in addressing. The demand by incumbent airlines to receive the same discounts as LCCs can result in an unforeseen reduction in aeronautical revenue. More specifically, at a number of small European airports where LCCs have begun operations, management have been under severe pressure to reduce charges to existing operators or risk losing their incumbent operators. 
A further problem faced by airports has been highlighted by the experience at one Eastern European airport where a LCC started services, an incumbent airline withdrew services, the LCC went bankrupt, therefore leaving the airport with less services than it had in the first place. The long term viability of each LCC and impact on incumbent operators needs careful evaluation when reaching a commercial agreement for new services.

\subsection{The need for transparency}

In their dealings with airline operators, airports require transparency and consistency. For example, Charleroi airport located to the south of Brussels and owned by the Walloon Regional Government, attracted Ryanair, in the face of severe competition from other airports in mainland Europe by offering them a financial package comprising reduced landing and handling charges, marketing of the airlines services, office space, pilot accommodation, in addition to payment for recruitment and training. In return, the airline agreed to a certain number of flights agreeing to work in partnership in order to promote tourism. As a result, the airport has expanded its terminal capacity, with plans for a runway extension plus rail link. The financial package was investigated by the EC following complaints from one of the airports competitors with a ruling that since Charleroi was owned by the regional government, a proportion of the incentives offered to Ryanair were perceived to be a state subsidy and therefore not permissible. The issue was therefore one of transparency with the financial incentive seen as a distortion of the air transport market. It would appear to be that all "start-up" deals must be transparent and non-discriminatory, being the same terms to any airline. If the arrangement had been with a private airport, the issue would not have arisen and as such, it may be that privately owned airports maybe more attractive to LCCs than those which are publicly owned.

\subsection{Benefits to local economy}

Some publicly owned airports have chosen to attract LCC with preferential deals in order to attempt to bring benefits to the local economy. Whilst such benefits may accrue, it can be difficult to predict/quantify. Airports need to be wary of the benefits likely to accrue to the local economy. For example, the owners of an airport in Southern Europe and the local tourist authority worked together in offering a package of concessions in order to attract a LCC to the airport with the intension of attracting tourists to the local economy (Francis et al., 2003 and 2004). As such, the airport paid aeronautical charges, provided a bus link to the town centre and made a financial contribution to advertising the service. On commencement of the service, it was found that passengers were using the airport as a transit point on their surface access journey to their holiday destination, leaving only marginal benefit to the local economy and little or no benefit to the airport, not least because it had only a small range of retail outlets. It is therefore important that the airport authorities carefully develop their business plan.

\subsection{Innovative/risk sharing contracts}

Management at a number of airports have sought to develop win-win commercial agreements with LCCs. A number of these contracts contain clauses that relate the charges to the number of passengers carried or the number of services operated. One airport reported a sliding scale whereby the aeronautical charges decreased in relation to the number of flights operated. Several airports had invested in software to monitor retail 
spend of passengers by flight number. This information was reported to be invaluable when negotiating aeronautical charges with LCCs and other operators. With detailed retail spend data, management can build up a picture of which passengers spend what, on what routes, at what time of day. The existence of this hard data provides a basis for negotiation that did not previously exist. One airport reported that certain routes at particular times of the day paid for themselves through passenger spend, yet charges were set to make a return for providing facilities to accommodate a network of services throughout the day. An interesting revelation has been that spending at peak times at some airports has been way below the forecast spend per passenger. This was thought to be due to the terminal being overcrowded and the long waiting time to pass through security that left little time for shopping once passengers arrived airside.

Some LCCs were said to be better to negotiate with than others. The situation for small regionally owned facilities was different than for airports that had the backing of a major airport operator. Negotiation of contracts that allow and motivate LCCs to build and grow their business were seen to be highly desirable since the relationship between airline and airport is symbiotic.

\section{Conclusions}

The impact of LCCs on airports is anything but uniform. LCCs have proved highly beneficial to some airports, whilst for others the benefits have been short lived or have failed to materialise. Experience seems to suggest that while individual operators may come and go, the low cost model is durable and that the passengers they can bring to an airport (particularly when it is underutilised) may enable both airport and airline to achieve a mutually beneficial position.

The growth of LCCs has given rise to a parallel network of airports developing. This parallel networks provides alternative capacity and opportunity to the traditional hub spoke airport network. The use of secondary airports offers benefits to the airlines and potentially to passengers. For airport management, however, there are a range of important issues that need to be considered, many being encountered for the first time.

There are a number of opportunities and threats afforded by the growth in the low cost sector. Airport management need to weigh up each opportunity on its relative merits in both the short and the long term. It is important for airport management to assess which airlines will deliver benefits to the airport in the long term, to be aware of those that may only exist for a short period of time or be prone to withdraw services at short notice and to negotiate commercial agreements accordingly. Any investment decisions made relating to infrastructure cater for LCCs should consider the sustainability of the relationship.

The airline-airport relationship is dynamic and the traditional airports are challenged in terms of if and how they should accommodate LCCs. The LCC market now comprises $12 \%$ of the world scheduled flights and is forecast to grow - as such, it is clearly a market worth considering. Airports beware! - there are opportunities but information is key to a successful airport-airline relationship. Information allows them to monitor and evaluate the potential for non-aeronautical revenue and the longevity of the relationship. 


\section{$6 \quad$ References}

Barrett, S. (2004) “The Sustainability of the Ryan Air Model,” Journal of Air Transport Management, 10: 89-98.

Caves, R. and G. Gosling (1999) Strategic Airport Planning. Pergamon: Oxford.

Creaton, S. (2004) Ryannair: How a Small Irish Airline Conquered Europe. Aurum Press: London.

de Neufville, R. (2004) "Current Design Challenges for Airports Worldwide," Transportation Research Board, Washington D.C. 11-15, January.

Dixon, T. (2005) “Low cost Flights Boom,” Airliner World, 6, p.28.

Dixon, T. (2005) “LOT’S New Offshoot,” Airliner World, March, p.12.

Dixon, T. (2005) “SkyEurope Drops Warsaw,” Airliner World, May, p.7.

Francis, G., A. Fidato, and I. Humphreys (2003) “Airport Airline Interaction,” Journal of Air Transport Management, 9: 267-273.

Francis, G, I. Humphreys, and S. Ison (2004) Airports' Perspectives on the Growth of :owcost Airlines and the Remodeling of the Airport-airline Relationship," Tourism Management, 25: 507-514.

Gillen, D., and A. Lall (2004) Competitive Advantage of Low-cost Carriers: Some Iimplications for Airports,” Journal of Air Transport Management, 10: 41-50.

Lawton, T., and S. Solomko (2005) "When Being the Lowest Being Cost is Not Enough: Building a Successful Low-fare Airline Business Model in Asia," Journal of Air Transport Management, 11: 355-362.

Nicholls, M. (2005) “The Changing Face of Schiphol,” Airliner World, 6: 56-61.

O'Connell, J., and G. Williams (2005) "Passengers' Perceptions of Low Cost Airlines and Full Service Carriers,” Journal of Air Transport Management, 11: 259-272. 